\title{
Determination of the Consistency in the Geometric Layout of a Mountainous Topography Road Based on the Determination of the Vehicle Operating Speed Profile Measured Through Radar
}

\author{
Fernando Jove Wilches $^{1}$, Jorge Luis Argoty Burbano ${ }^{2}$ and Álvaro Rafael Caballero Guerrero ${ }^{3}$ \\ ${ }^{1}$ Department of Civil Engineering, Universidad de Sucre, Sincelejo, Sucre, Colombia. \\ ${ }^{2}$ Department of Civil Engineering, Universidad de Nariño, San Juan de Pasto, Nariño, Colombia. \\ ${ }^{3}$ Department of Civil and Environmental Engineering, Universidad del Norte, Barranquilla, Colombia.
}

\author{
ORCIDs: 0000-0002-2080-4036 (Fernando), 0000-0001-6661-1398 (Jorge), 0000-0002-3567-9135 (Álvaro)
}

\begin{abstract}
The speed of vehicular flow is one of the most important variables to characterize the quality of the service provided to road users, which not only greatly influences the determination of Capacity and Service Levels, but also, that through the knowledge of the operating speeds, the traffic speeds of the different elements that make up the geometric layout (curves and tangents in plan) and the design speed within a particular road section, it is possible to determine the consistency geometric design, which in general terms, expresses the degree of adequacy between the behaviour of the road and the expectations of the driver. . For this work, it is presented, from the determination of the operating speeds, obtained through the use of radar, the consistency in the geometric design along a road section located in the southwest of Colombia and developed in mountainous topography, in which it was possible to evidence the existence of inconsistency in the geometric design in a significant number of elements of the way, which can generate unsafe conditions for road users
\end{abstract}

Keywords: Operating speed profile, consistency, geometric design

\section{INTRODUCTION}

Speed corresponds to one of the main indicators to measure the quality of the operation of a transport system, because it involves aspects such as safety, comfort, time and economy during the journey [1], [2]. An efficient transport system can be measured by the quality of the road system and the time used to make the journey along it, with which speed takes on a high degree of importance, which is why it needs to be determined, analyzed, regulated and controlled, in order to create a balance between the user, the vehicle and the road infrastructure [2].

Speed is so important that it is usually the reference parameter used to measure the level of service of a road, offering the driver safety, comfort and speed when transporting [3]. Therefore, it is very important to know the characteristic operating speed of a road corridor, which corresponds to the maximum average speed at which a driver can circulate on a given section of road, under favorable weather conditions, prevailing traffic conditions and without exceeding the safe speed at any time, circulating under free flow conditions [4]; since through this, a relationship could be established with the geometric characteristics of the road, in order to evaluate the consistency of a certain section, which is highly correlated with road safety [5], [6].

Consistency in the geometric design of a road can be defined as the degree of adequacy between the behaviour of the road and the driver's expectations [7]. Within the methods to estimate consistency, the study of operating speed is considered the simplest way to carry it out [8], hence some authors such as Mclean (1981) [9] consider that the main cause of Inconsistency of the designs is related to the difference between the design speed and the operating speed [10]; and Lamm (1986) [7] adopts this postulate and builds its consistency criteria based on successive field studies.

To determine the operating speed within a road element, whether it is shaped in a tangent or a curve, it is necessary to carry out a study of spot speeds, which seeks to measure the quality of traffic movement, through the two components of spot speed, that is, the mean temporal and spatial velocity; and of the travel speed and the walking speed [2].

On-site field speed studies are performed to estimate the speed distribution of vehicles in a vehicle flow and at a specific location on a highway. An on-site field speed study consists of recording the speed of a sample of vehicles at a specific location. The speed characteristics identified will be valid only for the traffic and environmental conditions that exist at the time of study [4].

The main objective of this work has been to determine the operating speed profiles, for the case of cars, buses and twoaxle trucks, which correspond to the most representative vehicles of the road corridor under study, in order to evaluate the consistency in the geometric design along a section of highway approximately 6.0 kilometres in length, located between K6 + 886.28 and K13 + 043.05 of the Pasto - Mojarras Highway, towards the southwest of Colombian country.

\section{MATERIALS AND METHODS}

II.I Aspects used for the evaluation of the consistency of the geometric design

To carry out the evaluation of the consistency of the geometric design of the road section under study, some basic aspects 
established in the Lamm procedure will be used, which is based on three criteria, of which the first two will be used, as they are the most used by most authors and on which there is more experience.

- Criterion I: comparison between design speed and operating speed, which is a good indicator of the inconsistency that may exist in a particular element.

- Criterion II: comparison of operating speeds between consecutive elements of the road layout. This is a good indicator of the inconsistency experienced by drivers traveling from one element to the next.

Table 1. Lamm consistency criteria

\begin{tabular}{|l|l|l|}
\hline $\begin{array}{l}\text { Consistency } \\
\text { Level }\end{array}$ & Criterion I (km / h) & Criterion II (km / h) \\
\hline Good & $\left|V_{85}-V_{d}\right| \leq 10$ & $\left|V_{85 i}-V_{85 i+1}\right| \leq 10$ \\
\hline Acceptable & $10 \leq\left|V_{85}-V_{d}\right| \leq 20$ & $10 \leq\left|V_{85 i}-V_{85 i+1}\right| \leq 20$ \\
\hline Poor & $\left|V_{85}-V_{d}\right|>20$ & $\left|V_{85 i}-V_{85 i+1}\right|>20$ \\
\hline
\end{tabular}

Table 1 shows the three levels of consistency considered to measure the quality of the service provided to users, based on the results obtained when applying the two Lamm criteria.

\section{II.II Characteristics of the elements that make up the section under study}

For the purposes of this work, 50 continuous elements were taken along the road section between $\mathrm{K} 6+886.28$ and $\mathrm{K} 13+$ 043.05 of the Pasto - Mojarras Highway, located in the southwest of Colombia. It is a typical layout of mountainous topography, with abundant CURVEture in plan and strong longitudinal slopes.

From the field work carried out, the basic information related to the elements of the layout in plan and profile was obtained, such as the type of element in plan evaluated (tangent or curve), the deflection of the curves, the radius, the maximum cant in the horizontal curves, the length of the elements, their location within the abscissa of the road and the characteristic longitudinal slope of each element evaluated.

Table 2 shows the characteristics of the elements of the road section under study.

\section{II.III Determination of the operating speeds in each element evaluated}

For the purposes of this work, the vehicles with the highest incidence in the global component of traffic along the road section under study were taken as a reference, which, according to the vehicle traffic volumes determined by the Instituto Nacional de Vías ( INVIAS) of Colombia, correspond to cars, buses and two-axle trucks (small and large).
To determine the minimum size of the spot speed sample, for each class of vehicle considered, the following expression was used [2]:

$$
N=\left(\frac{K * S}{E}\right)^{2}
$$

Where:

$\mathrm{N}$ : is the minimum number of spot speed data to record in each element.

$\mathrm{K}$ : constant that corresponds to a certain desired level of confidence, which takes the value of 2.00 , for a confidence level of $95.5 \%$.

E: allowed error in estimating the main speed of all traffic, which can be taken at $2.00 \mathrm{~km} / \mathrm{h}$.

$\mathrm{S}$ : average standard deviation of $8 \mathrm{~km} / \mathrm{h}$, as an empirical value for spot speeds on any type of road and traffic.

To determine the spot speed for each class of vehicle considered, the automatic method was used through the implementation of the Bushnell radar gun, whose receiver is designed to read the Doppler frequency, within the range of frequencies between $360 \mathrm{~Hz}$ and $43 \mathrm{KHz}$, capable of taking readings in 0.25 seconds [11]. It should be noted that this field work was carried out in each element and for each direction of circulation independently, respecting in each case the minimum size of the sample, which according to equation (1), turned out to be 64 readings of speed.

\section{RESULTS AND DISCUSSIONS}

\section{III.I Obtaining the traffic speed for each element}

For the determination of the specific velocities in each horizontal curve, these were found as a function of the radius and the maximum cant, which were obtained from planes and direct measurements made in the field.

For the case of the horizontal tangents, the traffic velocity was assigned the highest of the specific velocities of the curves adjacent to it.

In Table 3, the result obtained for the assignment of the traffic speed of each element is presented.

\section{III.II Obtaining the design speed of the section}

According to the Manual de Diseño Geometrico (INVIAS 2008), with regard to the design speed of a homogeneous section, it is defined according to the category of the road and its topographic characteristics [12], according to what is indicated in Table 4

Notwithstanding the foregoing, taking into account that the road under study was designed and built long before Table 4 came into force, the characteristics of the road corridor, as it is developed in mountainous terrain, has very poor specifications, which is why for the purposes of this work, will be taken as the project speed, the minimum traffic speed found in the allocation of speeds along the section under study, that is, 40 $\mathrm{km} / \mathrm{h}$. 
International Journal of Engineering Research and Technology. ISSN 0974-3154, Volume 13, Number 10 (2020), pp. 2588-2595

(C) International Research Publication House. https://dx.doi.org/10.37624/IJERT/13.10.2020.2588-2595

Table 2. Characteristics of the elements of the road section

\begin{tabular}{|c|c|c|c|c|c|c|c|c|c|}
\hline $\begin{array}{l}\text { ELEMENT } \\
\text { NUMBER }\end{array}$ & $\begin{array}{c}\text { TYPE OF } \\
\text { ELEMENT }\end{array}$ & SENTIDO & DEFLECTION & RADIUS & $\begin{array}{c}\text { CANT } \\
(\%)\end{array}$ & $\begin{array}{l}\text { ELEMENT } \\
\text { LENGTH }\end{array}$ & $\begin{array}{l}\text { INITIAL } \\
\text { ABSCISA }\end{array}$ & $\begin{array}{c}\text { FINAL } \\
\text { ABSCISA }\end{array}$ & SLOPE (\%) \\
\hline 1 & TANGENT & & & & & 285.605 & KM 6+886,282 & KM 7+171,887 & 6.148 \\
\hline 2 & CURVE & Right & $40^{\circ} \quad 19^{\prime} 51^{\prime \prime}$ & 116.698 & $7.28 \%$ & 82.145 & KM 7+171,887 & KM 7+254,032 & 6.148 \\
\hline 3 & TANGENT & & & & & 103.768 & KM 7+254,032 & KM 7+357,800 & 6.148 \\
\hline 4 & CURVE & Left & $48^{0} \quad 55^{\prime} 02^{\prime \prime}$ & 101.552 & $5.53 \%$ & 86.702 & KM $7+357,800$ & KM 7+444,502 & 6.148 \\
\hline 5 & TANGENT & & & & & 225.907 & KM 7+444,502 & KM 7+670,409 & 6.148 \\
\hline 6 & CURVE & Right & $100^{\circ} \quad 10^{\prime} 21$ & 65.633 & $8.46 \%$ & 114.749 & KM 7+670,409 & KM 7+785,158 & 6.148 \\
\hline 7 & TANGENT & & & & & 106.418 & KM 7+785,158 & KM 7+891,576 & 6.148 \\
\hline 8 & CURVE & Left & $83^{0} \quad 09^{\prime} 40^{\prime \prime}$ & 51.471 & $8.75 \%$ & 74.707 & KM 7+891,576 & KM 7+966,283 & 6.148 \\
\hline 9 & TANGENT & & & & & 54.74 & KM 7+966,283 & KM 8+021,023 & 6.148 \\
\hline 10 & CURVE & Right & $66^{0} 38^{\prime} 49^{\prime \prime}$ & 60.728 & $10.22 \%$ & 70.64 & KM 8+021,023 & KM 8+091,663 & 6.148 \\
\hline 11 & TANGENT & & & & & 31.751 & KM 8+091,663 & KM $8+123,414$ & 6.148 \\
\hline 12 & CURVE & Left & $56^{0} \quad 55^{\prime} 45^{\prime \prime}$ & 118.828 & $7.58 \%$ & 118.068 & KM $8+123,414$ & KM 8+241,482 & 6.148 \\
\hline 13 & TANGENT & & & & & 103.895 & KM $8+241,482$ & KM 8+345,377 & 6.148 \\
\hline 14 & CURVE & Left & $15^{0} \quad 44^{\prime} 31^{\prime \prime}$ & 193.188 & $4.07 \%$ & 53.078 & KM $8+345,377$ & KM $8+398,455$ & 6.148 \\
\hline 15 & TANGENT & & & & & 85.341 & KM $8+398,455$ & KM 8+483,796 & 6.148 \\
\hline 16 & CURVE & Right & $65^{\circ} 36^{\prime} 00^{\prime \prime}$ & 85.934 & $5.53 \%$ & 98.389 & KM 8+483,796 & KM $8+582,185$ & 6.148 \\
\hline 17 & TANGENT & & & & & 40.512 & KM $8+582,185$ & KM 8+622,697 & 6.148 \\
\hline 18 & CURVE & Right & $34^{0} \quad 52^{\prime} 25^{\prime \prime}$ & 155.015 & $6.12 \%$ & 94.351 & KM 8+622,697 & KM $8+717,048$ & 6.148 \\
\hline 19 & TANGENT & & & & & 423.775 & KM $8+717,048$ & KM 9+140,823 & 6.148 \\
\hline 20 & CURVE & Left & $61^{0} \quad 44^{\prime} 09^{\prime \prime}$ & 87.229 & $8.16 \%$ & 93.989 & KM 9+140,823 & KM 9+234,812 & 6.148 \\
\hline 21 & TANGENT & & & & & 40.704 & KM 9+234,812 & KM 9+275,516 & 6.148 \\
\hline 22 & CURVE & Right & $44^{0} \quad 18^{\prime} 30^{\prime \prime}$ & 111.161 & $8.16 \%$ & 85.964 & KM 9+275,516 & KM 9+361,480 & 6.148 \\
\hline 23 & TANGENT & & & & & 141.439 & KM 9+361,480 & KM 9+502,919 & 6.148 \\
\hline 24 & CURVE & Right & $43^{0} \quad 12^{\prime} 49^{\prime \prime}$ & 138.133 & $5.24 \%$ & 104.183 & KM 9+502,919 & KM 9+607,102 & 5.027 \\
\hline 25 & TANGENT & & & & & 69.472 & KM 9+607,102 & KM 9+676,574 & 5.027 \\
\hline 26 & CURVE & Left & $52^{0} \quad 22^{\prime} 35^{\prime \prime}$ & 102.193 & $8.16 \%$ & 93.419 & KM 9+676,574 & KM 9+769,993 & 5.027 \\
\hline 27 & TANGENT & & & & & 166.655 & KM 9+769,993 & KM 9+936,648 & 5.027 \\
\hline 28 & CURVE & Left & $22^{\circ} \quad 40^{\prime} 19^{\prime \prime}$ & 177.031 & $5.53 \%$ & 70.051 & KM 9+936,648 & KM 10+006,699 & 5.027 \\
\hline 29 & TANGENT & & & & & 99.511 & KM 10+006,699 & KM $10+106,210$ & 5.027 \\
\hline 30 & CURVE & Right & $68^{0} 59^{\prime} 15^{\prime \prime}$ & 101.448 & $8.46 \%$ & 122.149 & KM $10+106,210$ & KM $10+228,359$ & 5.027 \\
\hline 31 & TANGENT & & & & & 80.981 & KM 10+228,359 & KM $10+309,340$ & 5.027 \\
\hline 32 & CURVE & Left & $41^{0} 34^{\prime} 52^{\prime \prime}$ & 146.644 & $4.37 \%$ & 106.424 & KM $10+309,340$ & KM 10+415,764 & 5.027 \\
\hline 33 & TANGENT & & & & & 843.146 & KM 10+415,764 & KM $11+258,910$ & -6.851 \\
\hline 34 & CURVE & Right & $75^{\circ} \quad 58^{\prime} 28^{\prime \prime}$ & 68.316 & $8.16 \%$ & 90.587 & KM $11+258,910$ & KM 11+349,497 & -6.851 \\
\hline 35 & TANGENT & & & & & 75.163 & KM $11+349,497$ & KM 11+424,660 & -6.851 \\
\hline 36 & CURVE & Left & $\begin{array}{ll}59^{0} & 15^{\prime} 35^{\prime \prime}\end{array}$ & 87.625 & $5.24 \%$ & 90.628 & KM 11+424,660 & KM $11+515,288$ & -6.851 \\
\hline 37 & TANGENT & & & & & 32.472 & KM $11+515,288$ & KM $11+547,760$ & -6.851 \\
\hline 38 & CURVE & Right & $46^{0} \quad 35^{\prime} 05^{\prime \prime}$ & 96.115 & $7.58 \%$ & 78.147 & KM $11+547,760$ & KM 11+625,907 & -6.851 \\
\hline 39 & TANGENT & & & & & 33.323 & KM 11+625,907 & KM $11+659,230$ & -6.851 \\
\hline 40 & CURVE & Right & $48^{0} \quad 20^{\prime} 02^{\prime \prime}$ & 91.364 & $6.99 \%$ & 77.073 & KM $11+659,230$ & KM 11+736,303 & -6.851 \\
\hline 41 & TANGENT & & & & & 79.977 & KM 11+736,303 & KM 11+816,280 & -6.851 \\
\hline 42 & CURVE & Left & $\begin{array}{ll}157^{0} & 22^{\prime} 02 \\
\end{array}$ & 101.272 & $8.75 \%$ & 278.151 & KM $11+816,280$ & KM 12+094,431 & -6.851 \\
\hline 43 & TANGENT & & & & & 136.689 & KM 12+094,431 & KM $12+231,120$ & -6.851 \\
\hline 44 & CURVE & Left & $40^{\circ} 55^{\prime} 48^{\prime \prime}$ & 149.548 & $6.12 \%$ & 106.831 & KM $12+231,120$ & KM 12+337,951 & -6.851 \\
\hline 45 & TANGENT & & & & & 54.779 & KM $12+337,951$ & KM 12+392,730 & -6.851 \\
\hline 46 & CURVE & Right & $69^{0} 22^{\prime} 18^{\prime \prime}$ & 100.939 & $7.87 \%$ & 122.213 & KM 12+392,730 & KM 12+514,943 & -6.851 \\
\hline 47 & TANGENT & & & & & 171.987 & KM 12+514,943 & KM 12+686,930 & -6.851 \\
\hline 48 & CURVE & Right & $103^{0} \quad 28^{\prime} 39$ & 59.336 & $6.70 \%$ & 107.162 & KM 12+686,930 & KM 12+794,092 & -6.851 \\
\hline 49 & TANGENT & & & & & 37.938 & KM 12+794,092 & KM 12+832,030 & -6.851 \\
\hline 50 & CURVE & Left & $133^{0} 31^{\prime} 54$ & 90.546 & $6.41 \%$ & 211.023 & KM 12+832,030 & KM 13+043,053 & -6.851 \\
\hline
\end{tabular}


International Journal of Engineering Research and Technology. ISSN 0974-3154, Volume 13, Number 10 (2020), pp. 2588-2595

(C) International Research Publication House. https://dx.doi.org/10.37624/IJERT/13.10.2020.2588-2595

Table 3. Traffic speed for each element

\begin{tabular}{|c|c|c|c|c|c|c|c|c|c|}
\hline $\begin{array}{l}\text { ELEMENT } \\
\text { NUMBER }\end{array}$ & $\begin{array}{l}\text { TYPE OF } \\
\text { ELEMENT }\end{array}$ & RADIUS & CANT (\%) & $\begin{array}{l}\text { TRAFFIC } \\
\text { SPEED }\end{array}$ & $\begin{array}{l}\text { ELEMENT } \\
\text { NUMBER }\end{array}$ & $\begin{array}{c}\text { TYPE OF } \\
\text { ELEMENT }\end{array}$ & RADIUS & CANT (\%) & $\begin{array}{c}\text { TRAFFIC } \\
\text { SPEED }\end{array}$ \\
\hline 1 & TANGENT & & & 60 & 26 & CURVE & 102.193 & $8.16 \%$ & 60 \\
\hline 2 & CURVE & 116.698 & $7.28 \%$ & 50 & 27 & TANGENT & & & 60 \\
\hline 3 & TANGENT & & & 50 & 28 & CURVE & 177.031 & $5.53 \%$ & 45 \\
\hline 4 & CURVE & 101.552 & $5.53 \%$ & 40 & 29 & TANGENT & & & 60 \\
\hline 5 & TANGENT & & & 45 & 30 & CURVE & 101.448 & $8.46 \%$ & 60 \\
\hline 6 & CURVE & 65.633 & $8.46 \%$ & 45 & 31 & TANGENT & & & 60 \\
\hline 7 & TANGENT & & & 45 & 32 & CURVE & 146.644 & $4.37 \%$ & 40 \\
\hline 8 & CURVE & 51.471 & $8.75 \%$ & 45 & 33 & TANGENT & & & 50 \\
\hline 9 & TANGENT & & & 45 & 34 & CURVE & 68.316 & $8.16 \%$ & 50 \\
\hline 10 & CURVE & 60.728 & $10.22 \%$ & 45 & 35 & TANGENT & & & 50 \\
\hline 11 & TANGENT & & & 55 & 36 & CURVE & 87.625 & $5.24 \%$ & 40 \\
\hline 12 & CURVE & 118.828 & $7.58 \%$ & 55 & 37 & TANGENT & & & 50 \\
\hline 13 & TANGENT & & & 55 & 38 & CURVE & 96.115 & $7.58 \%$ & 50 \\
\hline 14 & CURVE & 193.188 & $4.07 \%$ & 40 & 39 & TANGENT & & & 50 \\
\hline 15 & TANGENT & & & 40 & 40 & CURVE & 91.364 & $6.99 \%$ & 45 \\
\hline 16 & CURVE & 85.934 & $5.53 \%$ & 40 & 41 & TANGENT & & & 60 \\
\hline 17 & TANGENT & & & 45 & 42 & CURVE & 101.272 & $8.75 \%$ & 60 \\
\hline 18 & CURVE & 155.015 & $6.12 \%$ & 45 & 43 & TANGENT & & & 60 \\
\hline 19 & TANGENT & & & 55 & 44 & CURVE & 149.548 & $6.12 \%$ & 50 \\
\hline 20 & CURVE & 87.229 & $8.16 \%$ & 55 & 45 & TANGENT & & & 55 \\
\hline 21 & TANGENT & & & 60 & 46 & CURVE & 100.939 & $7.87 \%$ & 55 \\
\hline 22 & CURVE & 111.161 & $8.16 \%$ & 60 & 47 & TANGENT & & & 55 \\
\hline 23 & TANGENT & & & 60 & 48 & CURVE & 59.336 & $6.70 \%$ & 40 \\
\hline 24 & CURVE & 138.133 & $5.24 \%$ & 40 & 49 & TANGENT & & & 40 \\
\hline 25 & TANGENT & & & 60 & 50 & CURVE & 90.546 & $6.41 \%$ & 40 \\
\hline
\end{tabular}

Table 4. Design Speed Values

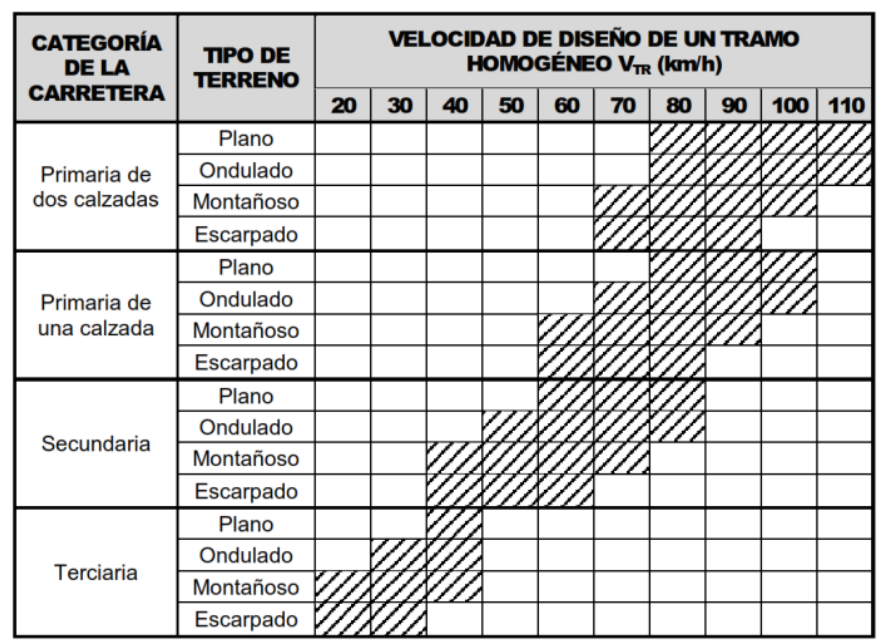

Source: Manual de Diseño Geometrico de Carreteras (INVIAS)

\section{III.III Obtaining the operating speed for each element}

With the collected field information, related to the recording of spot speeds for each category of traffic considered, and measured in the two directions of circulation independently, the statistical analysis was carried out, grouping the measured speeds in intervals of class, where the relative and accumulated frequencies could be established, in order to obtain the 85th percentile, which corresponds to the operating speed for each class of vehicle.

Based on the previous procedure, Table 4 was obtained, in which the operating speeds in the north-south and south-north directions are presented, for each element of the way section and discriminated in the different categories of traffic considered.

\section{III.IV Analysis of the consistency of the section through design and operating speeds}

For the evaluation of the consistency of the geometric layout of the road, speed profiles will be used, through which sites that present difficulties in the layout can be identified, which can be evidenced from the differences between the operating, traffic and design speeds.

The speed profiles allow to graphically and continuously demarcate along the abscissa, the speed of the section, the traffic speed and the operating speed for the cars, buses and trucks considered. 
International Journal of Engineering Research and Technology. ISSN 0974-3154, Volume 13, Number 10 (2020), pp. 2588-2595

(C) International Research Publication House. https://dx.doi.org/10.37624/IJERT/13.10.2020.2588-2595

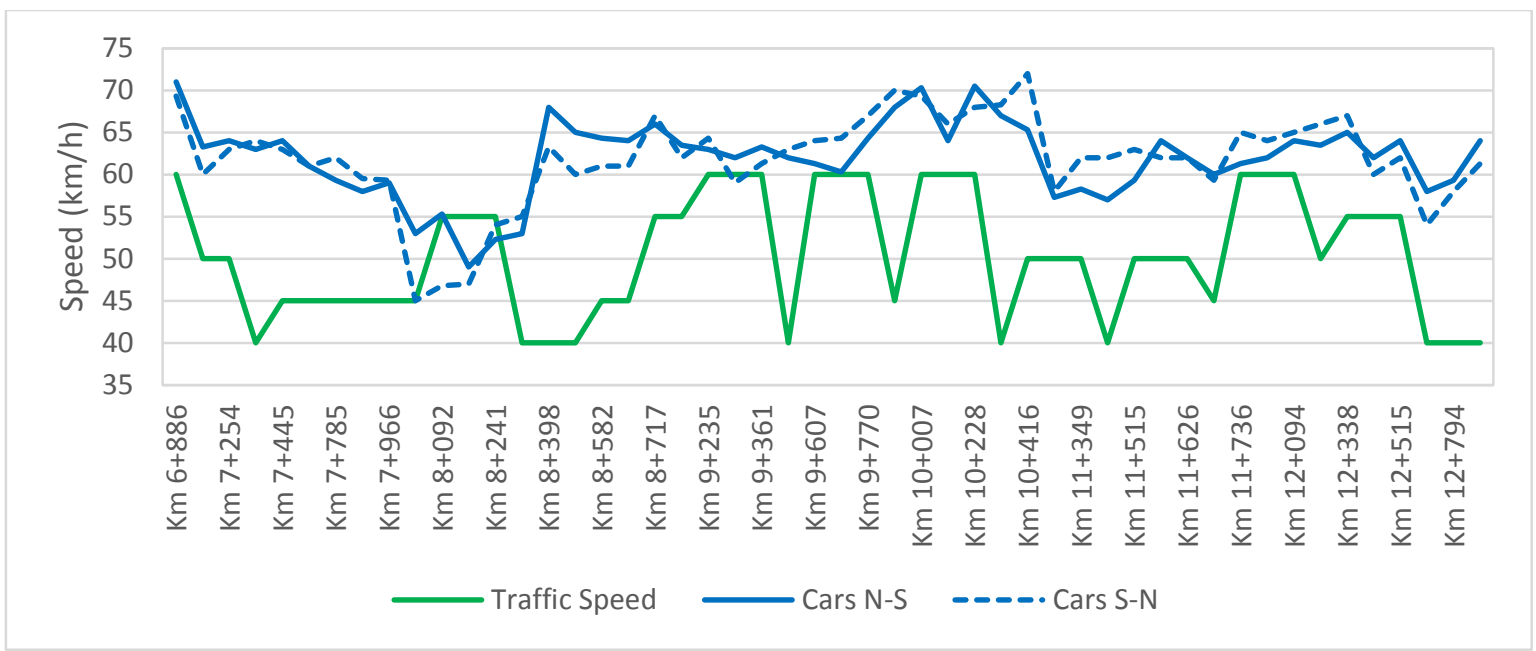

Fig. 1. Profile of operating speeds for automobiles and specific and design speeds for the K6 + 886.28 / K13 + 043.05 sector of the Pasto - Mojarras Highway

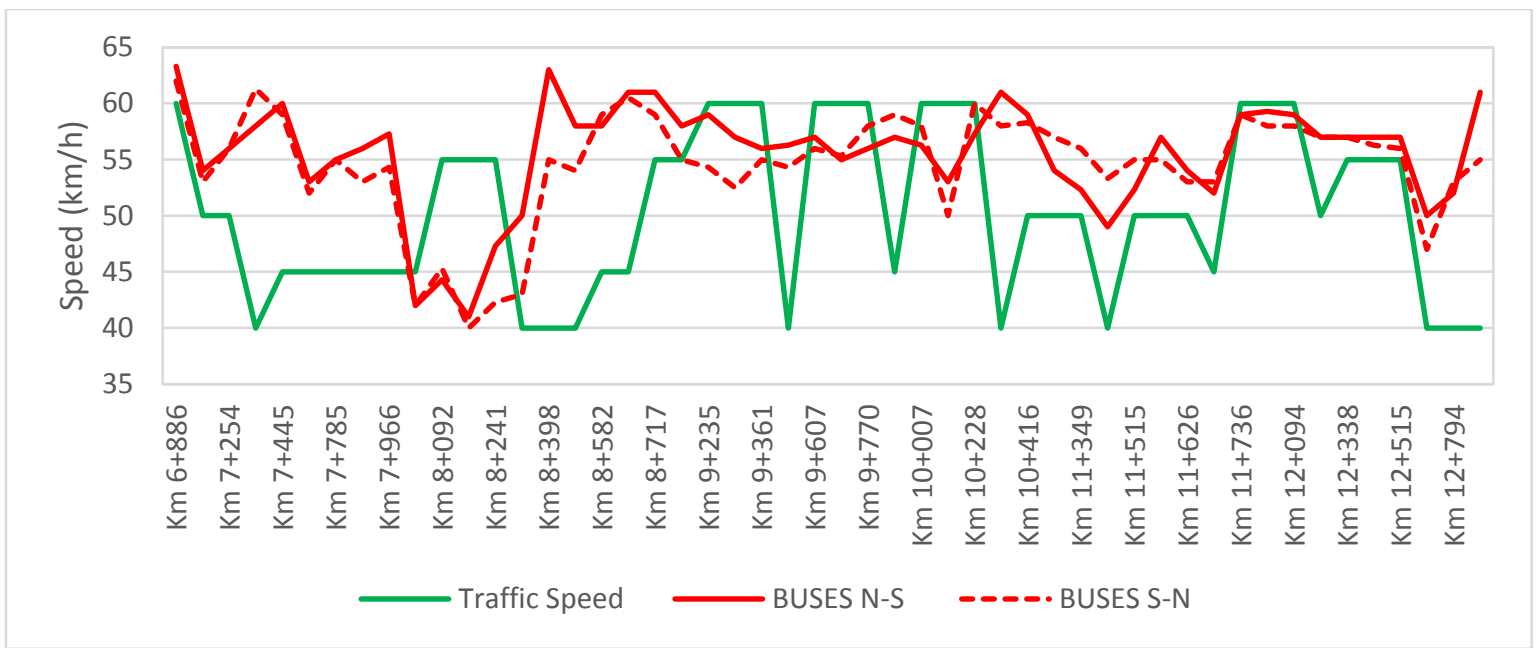

Fig. 2. Profile of operating speeds for buses and specific and design speeds for the K6 + 886.28 / K13 + 043.05 sector of the Pasto - Mojarras Highway

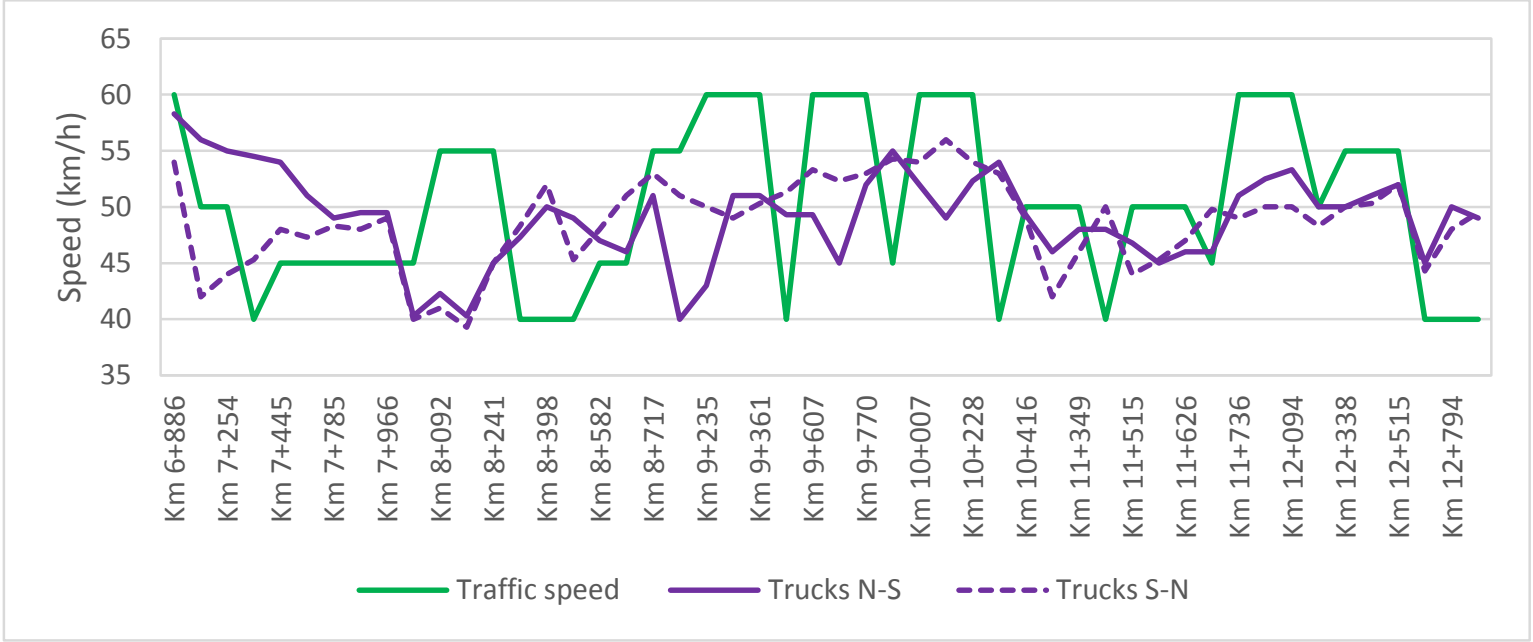

Fig. 3. Profile of operating speeds for two-axle trucks and specific and design speeds for the K6 + 886.28 / K13 + 043.05 sector of the Pasto - Mojarras Highway 
In Figures 1, 2 and 3, the operating speed profiles discriminated for each class of vehicle are presented, considering the two directions of movement. Similarly, in each of the graphs, the traffic speed profiles and design speed are also presented.

According to Figure 1, except for elements 11, 12 and 13, located between the abscissa $\mathrm{Km} 8+091,663$ and $\mathrm{Km} 8+$ 241,482 , in the case of automobiles, these present for the rest of the elements, in general, operating speeds, significantly higher than the specific speeds obtained along the route, which in some of these, especially in the tightest curves, could generate unsafe driving conditions and lead to the occurrence of accidents, attributable to excess speed.

According to Figure 2, in the case of buses, although less evident than in the case of automobiles, it can be observed that in more than $50 \%$ of elements along the route, the operating speeds recorded exceed at the traffic speeds and at the design speed, which is considered critical, since these vehicles normally carry a significant number of passengers, and speeding could cause accidents that can affect many people.

In Figure 3, it can be observed for the case of two-axle trucks that the operating speeds recorded are generally lower than those observed in cars and buses, with a large part of these being below the specific speeds. However, in practically all cases, the operating speeds recorded exceed the design speed of the section.

To complement the analysis, in tables 5 and 6, the elements with the lowest consistency are presented in the South - North and North - South directions, respectively. As can be seen, in 9 of the 50 elements, there are "poor" consistency conditions, especially in the case of cars and to a lesser extent for buses, especially in relation to Lamm's I criterion. This means that in a significant number of the elements of the route along the section under study, operating speeds are excessively higher than those of the design, which can generate adverse conditions for road safety.

Table 5. Summary of inconsistency elements - South-North direction

\begin{tabular}{|c|l|l|l|l|l|l|l|}
\hline \multirow{2}{*}{ ELEMENTO } & \multirow{2}{*}{ TIPO } & \multicolumn{3}{|c|}{ PRIMER CRITERIO DE LAMM } & \multicolumn{3}{c|}{ SEGUNDO CRITERIO DE LAMM } \\
\cline { 3 - 8 } & & \multicolumn{2}{|c|}{$\begin{array}{c}\text { CONSISTENCIA VELOCIDAD DE } \\
\text { OPERACIÓN VS VELOCIDAD DE DISENOO }\end{array}$} & $\begin{array}{l}\text { CONSISTENCIA VELOCIDAD DE OPERACIÓN } \\
\text { ENTRE ELEMENTOS CONSECUTIVOS }\end{array}$ \\
\cline { 3 - 8 } & & AUTOS & BUSES & CAMIONES & AUTOS & BUSES & CAMIONES \\
\hline 4 & CURVE & POOR & POOR & GOOD & GOOD & GOOD & GOOD \\
\hline 15 & TANGENT & POOR & ACEPTABLE & ACCEPTABLE & GOOD & GOOD & GOOD \\
\hline 24 & CURVE & POOR & ACEPTABLE & ACCEPTABLE & GOOD & GOOD & GOOD \\
\hline 28 & CURVE & POOR & ACEPTABLE & BUENA & GOOD & GOOD & GOOD \\
\hline 32 & CURVE & POOR & ACEPTABLE & ACCEPTABLE & GOOD & GOOD & GOOD \\
\hline 33 & TANGENT & POOR & GOOD & GOOD & ACCEPTABLE & GOOD & GOOD \\
\hline 36 & CURVE & POOR & ACEPTABLE & GOOD & GOOD & GOOD & GOOD \\
\hline 50 & CURVE & POOR & ACEPTABLE & GOOD & GOOD & GOOD & GOOD \\
\hline
\end{tabular}

Table 6. Summary of inconsistency elements - North-South direction

\begin{tabular}{|c|c|c|c|c|c|c|c|}
\hline \multirow{3}{*}{ ELEMENTO } & \multirow{3}{*}{ TIPO } & \multicolumn{3}{|c|}{ PRIMER CRITERIO DE LAMM } & \multicolumn{3}{|c|}{ SEGUNDO CRITERIO DE LAMM } \\
\hline & & \multicolumn{3}{|c|}{$\begin{array}{l}\text { CONSISTENCIA VELOCIDAD DE } \\
\text { OPERACIÓN VS VELOCIDAD DE DISEÑO }\end{array}$} & \multicolumn{3}{|c|}{$\begin{array}{l}\text { CONSISTENCIA VELOCIDAD DE OPERACION } \\
\text { ENTRE ELEMENTOS CONSECUTIVOS }\end{array}$} \\
\hline & & AUTOS & BUSES & CAMIONES & AUTOS & BUSES & CAMIONES \\
\hline 50 & CURVE & POOR & POOR & BUENA & GOOD & GOOD & GOOD \\
\hline 32 & CURVE & POOR & POOR & ACCEPTABLE & GOOD & GOOD & GOOD \\
\hline 28 & CURVE & POOR & ACCEPTABLE & GOOD & GOOD & GOOD & GOOD \\
\hline 24 & CURVE & POOR & ACCEPTABLE & GOOD & GOOD & GOOD & GOOD \\
\hline 16 & CURVE & POOR & ACCEPTABLE & GOOD & GOOD & GOOD & GOOD \\
\hline 15 & TANGENT & POOR & POOR & GOOD & ACCEPTABLE & ACCEPTABLE & GOOD \\
\hline 4 & CURVE & POOR & ACCEPTABLE & ACCEPTABLE & GOOD & GOOD & GOOD \\
\hline
\end{tabular}

On the other hand, in Figures 5, 6, 7 and 8, a summary of the consistency is presented according to each criterion considered, for each direction of circulation. In these graphs, it can be seen that the vehicles with the greatest inconsistencies are, in their order, from highest to lowest: cars, buses and trucks; and that
Lamm's Criterion I is the most critical, therefore, unfavorable conditions are to be expected in order to guarantee good road safety conditions, and that therefore, the road section under study may present a high potential for accidents. 


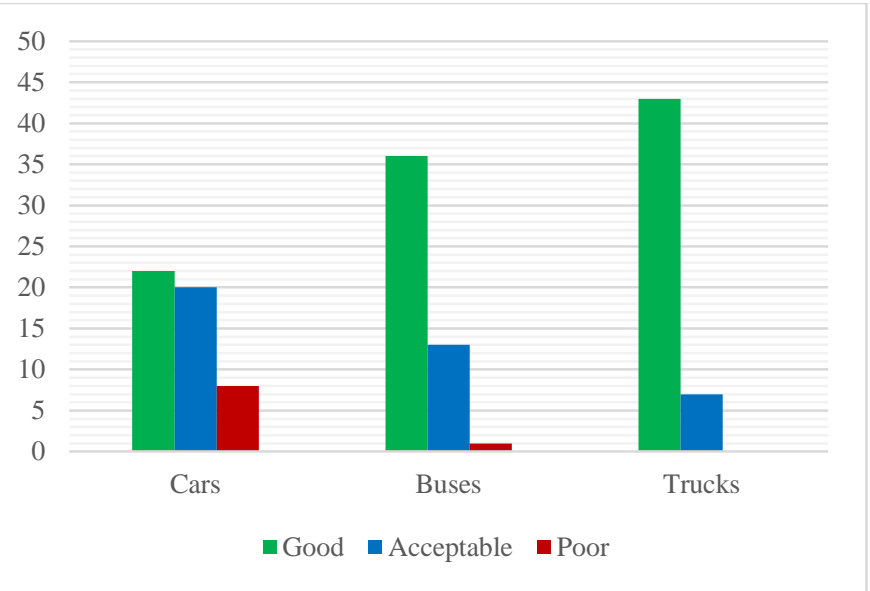

Fig. 4. Summary of consistency - Criterion I - South-North direction

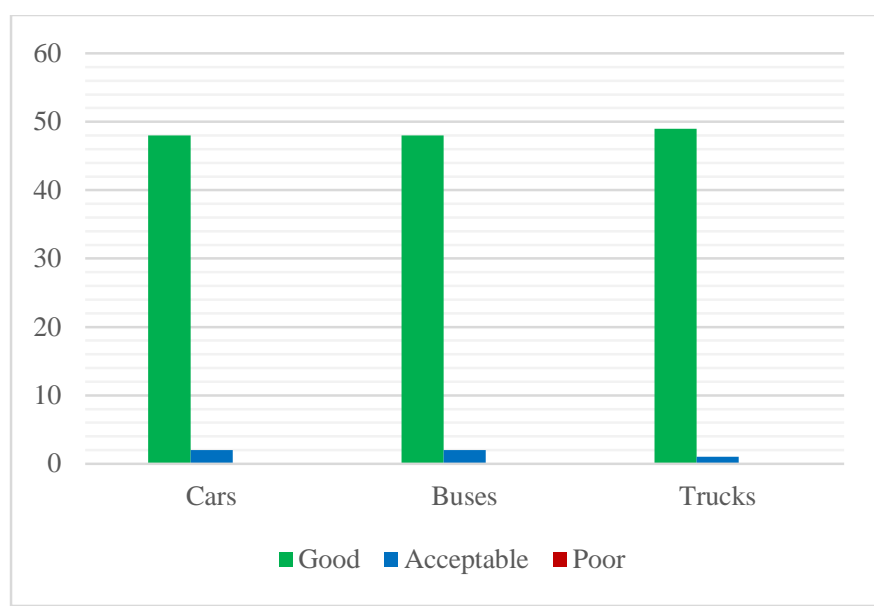

Fig. 5. Summary of consistency - Criterion II - South-North direction

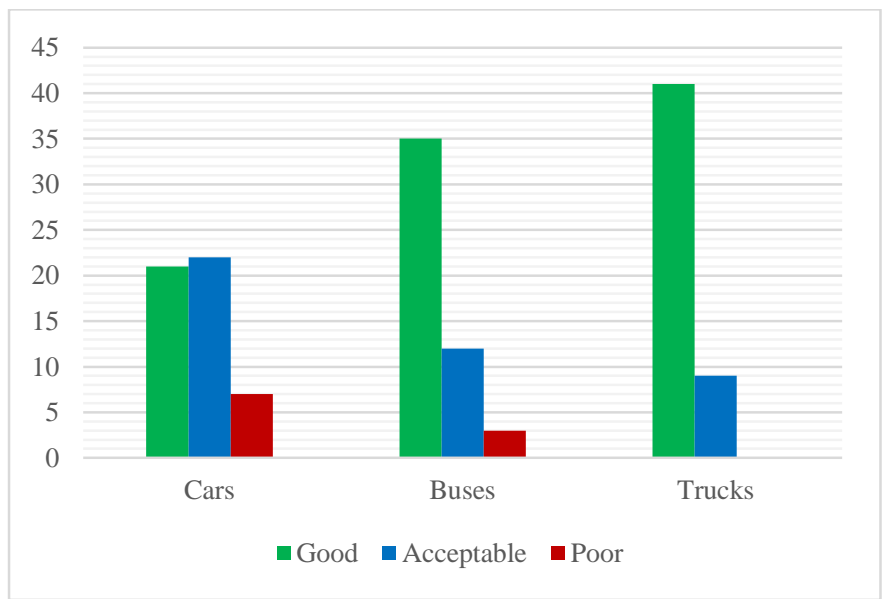

Fig. 6. Summary of consistency - Criterion I - North-South direction

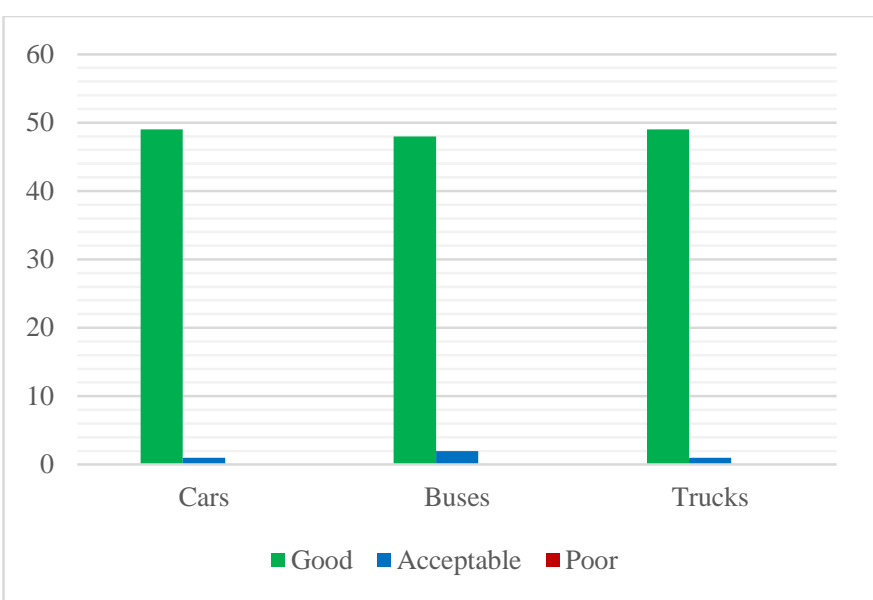

Fig. 7. Summary of consistency - Criterion II - North-South direction

\section{CONCLUSION}

In accordance with the results obtained in the studied road section, which is representative of the characteristic geometric layout of a large part of the topography throughout the Colombian territory, which is developed largely in mountainous terrain, it was determined that the geometric layout presents a significant number of elements with poor consistency, which can generate a high potential for the occurrence of accidents, leading to serious injuries and loss of life, taking into account that these roads, made up of a single carriageway, with a Only one lane enabled for each direction of traffic, a significant number of cargo and passenger vehicles travel simultaneously. That is why the authorities in charge are required to implement the necessary actions to improve the geometric characteristics of these road corridors, to make them more comfortable and safer.

\section{ACKNOWLEDGMENTS}

The author Jorge L. Argoty especially thanks the civil engineering students of the University of Nariño, María Ximena Mora and Diego Armando Ramírez for their collaboration and contributions to this project.

\section{REFERENCES}

[1] Bravo P, "Diseño de carreteras", Sexta edition, Carvajal S.A, Bogotá 1993.

[2] Garber N and Hoel L, "Ingeniería de tránsito y carreteras", tercera edition, Thomson editores, México, 2005.

[3] Gibreel GM, Easa SM, Hassan Y and El-dimeery, I.a. State of the art of highway geometric design consistency. Journal of Transportation Engineering, Vol. 125, 1999, pp. 305-313.

[4] Anderson IB, Bauer KM, Harwood DW and Fitzpatrick K. Relationship to safety of geometric design consistency measures for rural two-lane highways. Transportation Research Record: Journal of Transportation Research Board, Vol. 1658, 1999, pp. 43-51. 
[5] Pérez A, Camacho F and Garcia A, "La velocidad de operación y su aplicación en el análisis de la consistencia de carreteras para la mejora de la seguridad vial", Cuaderno tecnológico de la PTC, No. 06 (2011), Madrid.

[6] Cafiso S and La Cava G. Driving performance, alignment consistency and road safety real-world experiment. Transportation Research Record: Journal of the Transportation Research Board, Vol. 2102, 2009, pp. 1-8.

[7] ECHAVEGUEREN, Op. Cit. p. 7-26

[8] McLean J. Driver speed behavior and rural road alignment design. Traffic Engineering \& Control, Vol. 22, No. 4, 1981, pp. 208-211.

[9] Cafiso S. y La Cava . Driving performance, alignment consistency and road safety real-world experiment. Transportation Research Record: Journal of the Transportation Research Board, Vol. 2102, 2009, pp. 18.

[10] Mora M and Ramírez D, "Estudio de velocidad de operación y análisis del perfil de velocidades para la evaluación de la consistencia del trayecto Pasto Chachagui Km 5+000 - Km 19+000 mediante utilización de radar", Universidad de Nariño, San Juan de Pasto, Colombia, (2016).

[11] Ministerio de Transportes, Instituto Nacional de Vías, "Manual de diseño geométrico de carreteras", Bogotá, Colombia (2008). 